\title{
What is social equality? An Analysis of status equality as a strongly egalitarian ideal
}

\author{
Fourie, Carina
}

\begin{abstract}
What kind of equality should we value and why? Current debate centres around whether distributive equality is valuable. However, it is not the only (potentially) morally significant form of equality. David Miller and T. M. Scanlon have emphasised the importance of social equality - a strongly egalitarian notion distinct from distributive equality, and which cannot be reduced to a concern for overall welfare or the welfare of the worst-off. However, as debate tends to focus on distribution, social equality has been neglected and we do not have a clear understanding of what it is and why it might be valuable. This paper aims to address this gap.
\end{abstract}

DOI: https://doi.org/10.1007/s11158-011-9162-2

Posted at the Zurich Open Repository and Archive, University of Zurich ZORA URL: https://doi.org/10.5167/uzh-53362

Journal Article

Published Version

Originally published at:

Fourie, Carina (2012). What is social equality? An Analysis of status equality as a strongly egalitarian ideal. Res Publica, 18(2):107-126.

DOI: https://doi.org/10.1007/s11158-011-9162-2 


\title{
What is Social Equality? An Analysis of Status Equality as a Strongly Egalitarian Ideal
}

\author{
Carina Fourie
}

Published online: 22 July 2011

(C) Springer Science+Business Media B.V. 2011

\begin{abstract}
What kind of equality should we value and why? Current debate centres around whether distributive equality is valuable. However, it is not the only (potentially) morally significant form of equality. David Miller and T. M. Scanlon have emphasised the importance of social equality - a strongly egalitarian notion distinct from distributive equality, and which cannot be reduced to a concern for overall welfare or the welfare of the worst-off. However, as debate tends to focus on distribution, social equality has been neglected and we do not have a clear understanding of what it is and why it might be valuable. This paper aims to address this gap.
\end{abstract}

Keywords Social equality - Status - Egalitarianism - Distributive justice · David Miller · T. M. Scanlon

\section{Introduction}

In the US, black people were often expected to step off the pavement to get out of the way of approaching whites. ${ }^{1}$ In apartheid South Africa, black people were expected to call white men 'Baas', which means 'Boss' in Afrikaans, and white women, 'Madam'.2 Although typically this is what black people would call their white employers, they were often expected to call any white people, including strangers, 'Baas' or 'Madam'. White people, on the other hand, would often refer to

\footnotetext{
${ }^{1}$ See, for example, Jennie Brown's (1994, p. 26) biography of the civil rights activist, Medgar Evers.

2 For examples, see Nelson Mandela's (1995, pp. 145, 413) autobiography.

C. Fourie $(\bowtie)$

Ethics Research Institute, University of Zurich, Zollikerstrasse 117, 8008 Zurich, Switzerland e-mail: fourie@philos.uzh.ch
} 
adult blacks as 'boy' or 'girl'. These are examples of what can be called social inequality.

Now, it is obvious that inequalities between races, and particularly those of apartheid, whether inequalities in income distribution, power or political participation, for example, are gross violations of justice. The point of identifying social equality, however, is to say that the inequalities associated with having to get out of someone else's way merely because you belong to one group and they to another are wrong even if there are no (other) violations of justice ${ }^{3}$ associated with these inequalities. ${ }^{4}$ In this paper, I argue that social equality is a significant and distinct, yet neglected, component of what it means to treat people as equals. ${ }^{5}$

Discussions of equality in contemporary philosophy tend to be dominated by questions about the role of equality in distributive justice, in other words, by what can be called 'distributive equality'. Debate tends to centre around two primary topics: (1) the currency of justice, in other words, what kind of equality is important, e.g. resources, welfare, or capabilities, ${ }^{6}$ and (2) the pattern of distribution, in other words, whether equality per se is indeed significant, or whether justice will be better served through sufficiency (providing 'enough') or prioritising resources for the worst off. ${ }^{7}$

While debate centres on these two topics, social equality is mainly neglected. This neglect is regrettable, however. As Scanlon (2000) has highlighted, this form of equality is one of the few genuinely egalitarian notions of equality. In contrast, many theorists are beginning to doubt that what tends to be referred to as distributive equality has much to do with equality per se, and is, arguably, more to

\footnotetext{
${ }^{3}$ I discuss social inequalities as separable from violations of justice such as violations in the distributions of material goods and in power and political participation, for example, even though they often occur in conjunction with violations of justice or can lead to these violations of justice. However it is possible to see violations of social inequality as injustices in of themselves, beyond merely being morally objectionable. I take no particular stance on whether, as morally objectionable inequalities, social inequalities are also indeed injustices. I thus say (other) violations of justice to take account of the view that social inequalities could indeed, but need not be, violations of justice.

4 There could be practical reasons why some people (one group) should get out of other people's way (another group) - for example, it might be expected that if you are able-bodied or unencumbered, you should be expected to get out of the way of someone who has difficulty walking or is carrying heavy burdens. These would not be examples of social inequality-if anything they could be seen as means for trying to achieve equality through compensation.

5 As social inequalities tend to occur along with other kinds of injustices, the distinction I draw between social equality and overlapping but distinct notions such as distributive equality is primarily analytical.

6 See, for example, Rawls on primary goods as an example of the resourcist approach (1999, Sect. 11, pp. 54-55; Sect. 15, pp. 78-81. I will refer throughout this paper to this edition of A Theory of Justice, revised from the original of 1971) and Dworkin (1981a, b) for a defence of resourcism and criticism of welfarism. See also Sen (1982), Nussbaum (2000) and Anderson (2010) on capabilities, and Arneson $(1989,2006)$ for his defence of equal opportunity for welfare as the currency of justice, and criticism of the capabilities approach.

7 See, for example, Lucas (1965), Frankfurt (1987) and Crisp (2003) on sufficiency, and Parfit (1997) on the priority view as an alternative to valuing equality of welfare per se. For a defence of equality as valuable per se, see Temkin (1993, 2003). For a recent clarification and criticism of sufficiency, and its relationship to equality and priority, see Casal (2007), and for a clarification and defence of egalitariainism, see O’Neill (2008).
} 
do with alleviating the deprivation suffered by those who are worst off in society. If we want to identify when inequalities are wrong, we need to move beyond merely focusing on distributive equality. Although some theorists such as Miller (1998) and Scanlon (2000, n.d.) have provided nascent descriptions of social equality and its import, there is a lack of clarity about this notion of equality and, subsequently, we require much greater analysis. This paper aims to address this gap.

As the notion of social equality is neglected, and thus we need to start analysing social equality from the ground up, this paper will focus on asking and providing indepth answers to two rudimentary but essential questions: (1) What is social equality? and (2) Why is it valuable? Answering these questions can help to lay the groundwork for developing an extensive theory of social equality.

There are three sections to this paper. In the next section, I briefly highlight recent discussions about social equality to provide a context for the more in-depth analysis in the following sections, which aim, respectively, to answer the two primary research questions identified above. In the section after that, I describe social equality as consisting of, at least, one necessary condition-an opposition to hierarchies of social status-and identify a distinction between what I refer to as direct and indirect social inequalities. In the last section I consider the value of social equality, focusing particularly on the harms of inequality to those of higher status, mainly as this has been neglected.

\section{Intimations of Social Equality}

Miller (1998) has distinguished two types of equality: (1) distributive equality, which requires that certain social goods are distributed equally as a requirement of justice and (2) social equality, which identifies a social ideal-'the ideal of a society that is not marked by status divisions such that one can place different people in hierarchically ranked categories' (Miller 1998, p. 23). Most discussions of equality seem to be about the former kind, and yet Miller believes that it is important not to neglect social equality as it identifies 'a form of life in which people in a very important sense treat one another as equals' (Miller 1998, p. 32).

Scanlon (2000) considers a similar notion of equality, claiming it constitutes one of the few genuinely egalitarian reasons why we object to inequality. He identifies five primary reasons why it could be said to be important to eliminate inequalities, not all of which are actually egalitarian. Of these, however, he identifies 'stigmatizing differences in status' as one of the few reasons we have to reduce inequalities which is actually concerned with achieving equality per se. He claims that eliminating these differences in status is part of the ideal of a society in which people all regard one another as equals and that this ideal 'has played a more important role in radical egalitarian thinking than the idea of distributive justice which dominates much discussion of equality in our time' (Scanlon 2000, p. 43).

Raising an overlapping notion of equality, Anderson (1999) and Scheffler (2003) have voiced concerns about how a prominent contemporary theory of social justice, what Anderson has dubbed luck-egalitarianism, fails to be genuinely egalitarian because it does not show equal respect and concern for all citizens, in part because it 
creates stigmatizing or marginalising hierarchies of worth. Equality is not, Anderson and Scheffler argue, primarily to do with luck, or even with the distribution of social goods, but rather to do with relationships between people-an equal society will aim to abolish hierarchies of worth so that people are genuinely treated as equals.

Social equality, as highlighted by these theorists, seems to bear a greater resemblance to the foundational notions of equality often underlying real-life egalitarian movements than distributive equality does. ${ }^{8}$ As Anderson highlights, it seems to capture the type of equality and the emphasis on a common humanity at the heart of actual political movements better than a notion of equality of welfare or of resources (Anderson 1999, p. 288). Think, for example, of many civil rights movements, which are often fundamentally committed to a society in which people stand in equal relations to each other, meaning one race, for example, is not deemed better or worse than another. Social equality is also significant in the history of the theoretical debate about equality with philosophers such as Rousseau (1984) disparaging what can be called 'the Aristotelian argument', which presented inequalities in social rank as justified on the basis of natural inequalities (Dahrendorf 1972). Rousseau, on the other hand, considered hierarchies of status to be primarily socially derived-natural inequalities may compound social inequalities but they are neither the ultimate cause nor a justification for these inequalities (see, Rousseau 1984 Pt. 2, esp. pp. 114,118).

Despite the clear significance of the notion of social equality, it requires much closer analysis. An explicit, detailed model of social equality, distinguished analytically from (other) injustices has not yet been provided: Miller and Scanlon, for example, only provide us with clues as to what a society characterised by social equality would look like. If social equality is to form a meaningful answer to the question of which forms of equality are desirable, we need to know what it is. Although Miller may be right that '[i]t is possible to elucidate the ideal of social equality in various ways, but difficult to give it a sharp definition', we should not let this difficulty stop us from clarifying the notion (Miller 1998, p. 31).

\section{What is Social Equality? An Opposition to Status Hierarchies}

A common thread among discussions of social equality (and related notions) is that it is fundamentally opposed to what Scheffler refers to as 'hierarchies of social status' (Scheffler 2003, p. 22). Miller describes a society of equals as one 'that is not marked by status divisions such that one can place different people in hierarchically ranked categories, in different classes for instance' (Miller 1998, p. 23). Anderson describes inegalitarianism as a commitment to 'basing a social order on a hierarchy

\footnotetext{
8 This is not to say that distributive equality might not also be a significant notion. What I question is that it should be the only significant notion of equality. Often descriptions of a particular type of equality are associated with the claim that it is the only type of morally significant equality. This is not my claim about social equality. Furthermore, although it is possible to see social equality as a foundational notion and to use it as a basis to defend other forms of equality, I do not believe that social equality needs to be seen in this way. One could feasibly claim that it is simply one of a number of significant aspects of what we mean when we describe a society of equals.
} 
of human beings ranked according to intrinsic worth' (Anderson 1999, p. 312). An opposition to ranking people according to hierarchies of social status appears to be the central tenet of social equality. ${ }^{9}$ But what exactly does it mean to be opposed to hierarchies of social status? What are status hierarchies? We need to flesh out these ideas. In this section, I will (1) describe status hierarchies as expressions of inferiority and superiority, indicated by both an evaluation and an expression of that evaluation, and (2) distinguish between (a) direct social inequalities which unambiguously indicate inferior/superior treatment and (b) indirect inequalities which create status inequalities through, for example, particular distributions of social goods.

A status hierarchy occurs when a behaviour, social practice or policy expresses a particular kind of unequal relationship between a person or group of people, and others. More specifically, it is a relationship between inferiors and superiors. In this relationship, one person ${ }^{10}$ is deemed to be an inferior in relation to another person, who is either directly deemed to be a superior or who, by virtue of their relationship to an inferior person, automatically becomes the superior. ${ }^{11}$ Returning to the example of social inequality I used at the beginning of the paper, the act of stepping off the pavement at the approach of a white person reflects and reinforces the superiority of the white person over the inferior black person.

When one person is treated as a superior and another as an inferior this does not necessarily imply that the superior person is treated very well or that the inferior person is necessarily severely disadvantaged, or devalued. The point, when we refer to hierarchies of social status, is the nature of the relationship between social positions, not the absolute level of treatment. Subsequently, it is not that those

\footnotetext{
9 The term 'social' equality is ambiguous. For example, it could be used as a much broader term to indicate any socially-caused inequality. However, my use of the term, following on from Runciman (1967) and Miller (1998), separates social equality (or what can also be called status equality) from related, overlapping notions such as equality of power. It is for this reason, for example, that I do not discuss exploitation or domination, which are usually linked to economic and political power. As emphasised in the introduction, this is primarily an analytical distinction, and thus social inequalities are seldom found to be separate from other forms of inequalities in practice. It is necessary to draw such a distinction, however, precisely for the purposes of this paper, which is to determine what social equality is as a distinct, genuinely egalitarian ideal which cannot be reduced to other concerns, for example, about power and wealth. However, although I claim social inequalities cannot be reduced to other forms of inequality, power hierarchies will, of course, often also imply status inequality. What kind of a relationship there is between inequality of power and inequality of status requires greater exploration as a topic on its own.

${ }^{10}$ For ease of description, I will refer here to $a$ person in comparison to another person. Mainly, however, social inequalities occur between groups of people. Although it is possible to have (somewhat) personal status hierarchies, the hierarchies to which I am referring are those usually constructed by a social group or community or society, rather than an individual or isolated groups of individuals. Something similar can be said about those who are on the lower rungs of the hierarchy: although in practice it may be only one particular individual who is marginalised, perhaps they are the only black person in a small community, they are often marginalised because they belong to a particular social group or because they do not belong to a particular social group, or, most likely, a combination of both. However, I do not think that social equality is intrinsically group-related. An individual can still be treated as inferior even if this is not associated with any particular group membership.

11 Or vice versa-one person could be deemed superior in relation to another person, who is either directly deemed to be an inferior or who, by virtue of their relationship to a superior person, automatically becomes the inferior.
} 
devalued are necessarily treated badly or that those treated as superiors are privileged that is foremost the problem (although this is usually indeed what occurs in practice): it is that they are not treated as equals. This is what makes social equality strongly egalitarian.

Precisely what makes a notion of equality 'strongly' egalitarian is, of course, part of the debate surrounding the value of equality. However, in describing social equality as strongly egalitarian, I adopt Scanlon's description of what it means to be 'genuinely' egalitarian (Scanlon n.d., p. 6). Strongly egalitarian objections to inequality, Scanlon claims, are (1) comparative, meaning they are concerned with the relation between individual's positions or level of benefits, and (2) unspecific, meaning they are not 'concerned with the absolute levels of these benefits: it is the difference between the benefits enjoyed by the two groups that matters, not the failure of either of these to meet some specified minimum' (Scanlon n.d., p. 6).

A theory of social equality is comparative, being concerned with the relationship between individuals and their relative positions in a status hierarchy, and it is unspecific, in other words it is not concerned with the actual level of benefits or welfare of those on the hierarchy. This could be contrasted to a notion of distributive equality. As discussed in the introduction to this paper, many critics claim that distributive equality is not valuable per se and that what seems to be a concern for equality is actually a concern for something else, e.g. the deprivation of those who are worst off in society (see particularly, Parfit (1997) as example). In the last section of this paper, I will return to the discussion of how social equality seems to be a strongly egalitarian ideal by emphasising that it cannot be reduced to a concern for the welfare of the worst off.

Social equality, then, expresses an ideal where people stand in equal relation to each other rather than being treated as better or worse, inferior or superior. When someone is considered to be an inferior, this consists of both (1) an evaluation and (2) an expression of that evaluation. Consider the relationship between an individual bearing the title Doctor (Dr) and another with the title Mister (Mr) in a society in which great prestige and honour is associated with titles and those with lesser titles are treated as inferiors. We could say that the $\mathrm{Mr}(1)$ is valued less than the Dr, meaning he is considered to be, at least in certain ways, a lesser person, and (2) this evaluation finds some form of expression, such as in expectations, behaviour, and even policy. For example, the $\mathrm{Mr}$ is expected to act obsequiously, 'bowing', 'scraping' and 'fawning' in the presence of the Dr to indicate his inferior status. ${ }^{12}$ Being treated as superior also breaks down into (1) an evaluation and (2) an expression of that evaluation, but in this case it is a mode of expression that esteems or reveres, or, at least, treats the person deemed as superior to be of higher value than those who are inferior. Additionally, although status hierarchies have at least two levels by necessity, those treated as superior and those as inferior, it is also

\footnotetext{
12 I refer to Walzer (1983, p. xiii): 'This is the lively hope named by the word equality: no more bowing and scraping, fawning and toadying; no more fearful trembling; no more high-and-mightiness.' The overall example owes a debt to Walzer as well-he refers to a society of equals as a 'society of misters' (p. 256) - although note that in contrast, I will claim that we need to distinguish between titles, per se, and unequal relationships, which holds out the possibility that titles with a functional purpose are compatible with an equal society.
} 
possible for a hierarchy to be more complex and consist of layers of social stratification, each with implications for evaluation and the expression of evaluation-think of caste in India, for example.

The evaluation and its expression are both necessary in terms of describing how social positions on a status hierarchy are indicated. Evaluation provides a necessary condition for distinguishing between mere differences, on the one hand, and social inequalities, on the other. Consider our example of the titles 'Dr' and 'Mr'. In of themselves, these titles do not necessarily indicate social inequalities: we could imagine a society which conferred titles, but where no particular value was associated with any of the titles. Consider, for example, a society which conferred the title Doctor to medical doctors only to make them more easy to identify in a medical emergency (with the further proviso that in this society being a medical doctor is not necessarily considered to be more prestigious than other jobs). Subsequently, being a Dr does not make you any better than being a Mr, even though it signifies a difference. It is only once these differences have been associated with a particular evaluation, which leads to a ranking of the worth of the bearers of these titles, that social inequality would ensue. Even conferring the title Dr to someone with a $\mathrm{PhD}$, would not in of itself imply a hierarchy of worth-it only implies this if we associate some sort of value to having a higher education or a $\mathrm{PhD}$ in particular. We could imagine a society in which having a higher education was simply one of many options, none of which necessarily implied greater prestige than another. ${ }^{13}$

The ranking of social positions, Ralf Dahrendorf has emphasised, is central to the distinction between social differentiation, where different but essentially equal positions can be distinguished, and social stratification, where positions are ranked differently in terms of status (Dahrendorf 1972, pp. 90-91). Dahrendorf points out, for example, that a tendency to reduce status inequalities to a division of labour fails to make this important distinction-a division of labour per se implies differentiation rather than stratification:

From the point of view of the division of labour... there is no difference in rank between the director-general, the typist, the foreman, the fitter and the unskilled labourer... If in fact we do associate a rank order... with these ... activities, this is due to an additional act of evaluation which is neither caused nor explained by the division of labour (Dahrendorf 1972, p. 97).

While the aspect of evaluation, and not differentiation per se, is a necessary component, on its own it is insufficient to delineate social inequality-if I evaluated someone as inferior or superior but this never found any sort of expression, it is difficult to see how it could result in an unequal relationship between people. The actual expression of the evaluation, through individual behaviour or through policy, for example, is thus an essential part of what makes the relationship one of inferiority and superiority.

\footnotetext{
13 Although, of course, this might raise the question of why a differentiating title would be necessary if it did not indicate esteem, but this is different from the claim that giving someone a title is necessarily indicative of a particular status.
} 
Emphasising both the evaluative and the expressive components of social inequality are important analytically - they are not intended as a description of chronology or causation. I am not claiming that status hierarchies are formed in a particular chronological order, where people are first evaluated and ranked, and subsequently this evaluation finds form in some sort of expression. It may be tempting to explain injustices as caused by social inequality-in other words, it is because of the oppressors' belief in a particular group's inferiority that they are oppressed. Although this is possible, it is not necessary-one could treat someone as inferior without actually believing they are inferior. I am also not claiming that the evaluation made is necessarily conscious or intended, although in certain cases, such as that of the white supremacist, the evaluation and expression are clearly intended. However, even in the case of white supremacy, where there is an intentional claim of inferiority, causation is unlikely to be simplistic, and claims that other races are inferior could be rationalisation for economic exploitation, for example, rather than being, or rather than merely being, the cause of oppression or discrimination.

The idea that evaluations need not be made intentionally leads us to a distinction between two different kinds of social inequalities. We can call them (1) direct or (2) indirect. The former is an inequality of status which directly and unambiguously confers better status to some in comparison to others. Examples of these would be expecting certain individuals to look down when they are spoken to, or to speak only when spoken to (where these are indeed indicators of lower status in a specific society). ${ }^{14}$ On the other hand an indirect social inequality is foremost a difference or inequality of another kind (in other words, not a status inequality) but which indicates or leads to a social inequality. For example, it could be a social policy that seems to humiliate or marginalise a particular group of people, and thus by implication to treat them as inferiors, without any necessarily conscious intention on the part of those who developed and implemented the policy to confer inferior status on this group. Scanlon points to this distinction by referring to two major sources of stigmatizing differences of status. The first, corresponding to direct social inequalities, occur when 'institutions... treat some people in ways that could only be understood as intended to express the view that they were inferior' while the second, corresponding to indirect social inequalities, occur when 'institutional arrangements that, while they did not have the aim of expressing inferiority, nonetheless had the

\footnotetext{
14 Runciman (1967) highlights that social inequality can be identified by looking for culturally specific behaviours which treat individuals differently in terms of how much respect they are afforded, in contrast to behaviours which treat them differently in terms of praise. For example, respect might be indicated by bowing, while praise may be indicated by clapping, although these indicators will differ from society to society. Social inequality ensues then when we demand that some individuals bow in the presence of others, but it does not ensue when some individuals clap in the presence of others. I do not think, however, that Runciman's description is sufficient for distinguishing between behaviour that violates social equality and that which is consistent with it. Runciman's distinction would allow too much questionable behaviour. For example, he implies that a 'white skin appreciation' society, which purports to admire white skin in the same way as athletic ability is often admired, could be understood simply as a form of praise (Runciman 1967, p. 222). However, in a non-ideal world marked by a history of the oppression of, and continued discrimination against, non-white races, this, even if it is only a form of praise when considering the type of behaviour alone, seems far too close to an understanding of white superiority that it does not seem consistent with social equality.
} 
effect of giving rise to feelings of inferiority on the part of most reasonable citizens' (Scanlon 2000, p. 52).

Indirect social inequalities demonstrate a significant relationship between social inequality and other forms of inequalities, such as for example, those of wealth and power. Other inequalities can create or reinforce social inequality, and thus a notion of social equality could provide a foundation for evaluating other inequalities and, more specifically, for example, for evaluating principles for the distribution of social goods. Unequal distributions of certain social goods could create hierarchies of social status. In order to achieve a society of equals, goods would need to be distributed in ways which did not either create or reinforce unequal social status. As Miller puts it: 'If we want our society to be egalitarian, then we will try to shape our distributive practices so that the emergence of hierarchy is discouraged' (Miller 1998, p. 34).

It is within this context that we can understand part of Anderson's (1999) criticism of luck-egalitarianism-she claims, for example, that luck-egalitarian policies will (a) allow individuals who make reasonable but ultimately unlucky choices to become destitute and (b) humiliate the disadvantaged by branding them as stupid, ugly or talentless. Although there may be no genuine belief that these individuals are inferior, or there may be no intention to treat them as second-class citizens, one could argue that these policies do indeed treat these individuals as inferior. $^{15}$

Large income gaps may also provide an example of a distributive inequality which leads to social inequality. Scanlon claims that these gaps provide the most obvious example of how status inequalities are created by certain kinds of distributions - those who live at the bottom end of large wealth and income inequalities, he claims, are shamed and humiliated by them (Scanlon 2000, p. 52). Other examples could be policies which marginalise or exclude certain groups by denying them social goods such as health care.

While one of the negative aims of a society of equals would be to reduce or eliminate policies and activities which created or reinforced social inequalities, we could look to the positive side of the question and consider, what a society of equals would indeed look like. In other words, and for example, how would the basic institutions of society have to be designed and which distributive policies would need to be put in place to uphold socially equal relationships between individuals? Miller claims that social equality requires a complex equality across separate spheres of distribution, where social equality will be achieved by having many autonomous distributive spheres, rather than 'an across-the-board simple distributive equality' (Miller 1998, p. 35). ${ }^{16}$ An alternative is Anderson's claim that a capabilities approach to distributive justice follows from the claim that citizens

\footnotetext{
${ }^{15}$ Consider, as a similar example, Jonathan Wolff's discussion of how opportunity conceptions of justice humiliate welfare claimants by requiring 'shameful revelation' (Wolff 1998, p. 114).

16 For more on separate spheres, see Walzer (1983) and Miller (1995). Scanlon claims that although Walzer's notion of complex equality is open to much criticism as a theory of distributive justice, it could be seen as feasible if limited merely to an approach for reducing the conflict between feelings of inferiority and inevitable inequalities which arise from the values associated with skills and accomplishment. See Scanlon (2000, p. 56).
} 
should stand in relations of equality to one another, as '[c]itizens [thus] have a claim to a capability set sufficient to enable them to function as equals in society' (Anderson 2010, p. 83).

As my purpose in this paper is only to focus on what social equality is and why it is valuable, I will not take a stance on which principles or patterns of distributive justice are likely to violate social equality and which are most compatible with social equality. This is beyond the scope of a paper which primarily aims to lay the groundwork for a theory of social equality. What should seem clear from the discussion, however, is that it is not self-evident what influence different forms of distributive justice would necessarily have on hierarchical relationships, and that, indeed, there may be many different social arrangements that could either lead to or lead away from social equality. Which will indeed be compatible with social equality is, partially, an empirical issue-whether particular policies lead to status hierarchies is something to be seen and tested. However, it is also open to interpretation - for example, whether luck-egalitarian policies are indeed violations of social equality needs to be explained and defended according to a robust theory of social equality. Subsequently, we first need to know precisely what social equality is and why it is important.

A theory of social equality could, therefore, be useful for evaluating principles of distributive justice, although it will seldom be self-evidently clear which distributions social equality demands. Such a theory could also help to complete the picture of what a society of equals would look like-something many theories of distributive justice seem unable to provide in isolation, at least partially because they tend to ignore 'informal' inequalities.

Social inequalities can be built into the formal legal and political framework of a society. Extreme examples would be the caste system in India, the system of racial classification in apartheid South Africa and the hierarchy of slaves, metics (resident aliens) and citizens in Ancient Greece. ${ }^{17}$ Status hierarchies need not, however, be legally coded and coercively enforced; they are often part of social structure without necessarily being part of a society's legal structure. Consider, for example, a social norm which directs those of lower status to stand when someone of higher status enters a room. Relationships of social inequality could thus be formal, codified and institutionalised, or they can be informal and can characterise how people interact on an everyday level, in private and socially, although usually they are both. With an emphasis on the justice of institutions, distributive justice is often silent about informal inequalities in civic life, the workplace, individual behaviour within the family, associations and so on. A number of theorists have highlighted this gap and argue that contemporary notions of distributive justice neglect what may be a significant element of a society of equals_-an egalitarian ethos (Wolff 1998; Mason 2000). Jonathan Wolff, for example, highlights that there may be 'goods' that depend on the attitudes people have toward each other and thus there is more to a society of equals than a fair scheme of the distribution of material goods. A notion

\footnotetext{
${ }^{17}$ For an explanation and history of the caste system see Bayly (1999). For a history of apartheid, see Louw (2004) and Terreblanche (2003). See Walzer (1983) on how the resident aliens of Ancient Athens, the metics, were often treated with contempt and denied political and welfare rights.
} 
of social equality, because it is focused primarily on relationships, rather than institutions, could be used to highlight the inequalities between individuals which stem from their attitudes and everyday behaviour. Subsequently, a theory of social equality may be a necessary part of developing a comprehensive description of a society of equals, as theories of distributive justice seem unlikely to be able to achieve this on their own. ${ }^{18}$

\section{The Value of Social Equality and the Harms of Inequality}

When we talk about what makes a society equal, besides other possible notions of equality, a notion of status equality seems essential. When some people are expected to act obsequiously towards others, even if there are no other associated violations of justice, this is not equality. To say that this is not equality seems quite clear. To claim, however, that violations of social equality are morally objectionable (independently of violations of justice that may result from them or may cause them) is quite another matter. Perhaps social inequality is distinct from (other) violations of justice but what, if anything, makes it morally objectionable?

There are two primary kinds of claims that could be made about the value of social equality. We could claim it has (1) intrinsic value or that it is constitutive of something that is intrinsically valuable, or it has (2) instrumental value, or we could refer to its negative effects. In this section I will (1) consider the intrinsic or constitutive value of social equality, while conceding that this is challenging to demonstrate, and (2) refer to the harms that result from social inequality, focusing particularly on the harms of superior treatment. While focusing on the ill effects of equality may seem unsatisfactory as this could indicate that equality is only instrumentally valuable and thus that a concern for equality is only weakly egalitarian, I will (3) highlight that this challenge does not apply to social equality and that a concern with social equality cannot be reduced to a concern with overall welfare or the level of welfare of the worst off.

\section{The Intrinsic or Constitutive Value of Social Equality}

For some it may be intuitively clear-treating an individual as inferior is inherently wrong. If this is so, then social equality can be said to have intrinsic value. The

\footnotetext{
18 Fraser (1997) and Young (1990) have also criticised theories of distributive justice in ways that have relevance for a notion of social equality. By focusing on cultural injustices and distinguishing these from distributive justice, Fraser's theory of recognition shares some important similarities with social equality. There is also some overlap between a notion of social equality and Iris Marion Young's politics of difference. Young criticises justice defined in distributive terms claiming that injustice should rather be understood in terms of domination and oppression, However, despite these overlaps, social equality is distinct from Fraser and Young's notions-social equality condemns a very specific type of the relationship, that represented by status hierarchies, and centres itself explicitly as a form of egalitarianism. It is both more specific and more strongly egalitarian than Fraser and Young's theories. Furthermore, unlike Young's understanding of justice, a notion of social equality does not (necessarily) imply that we should emphasise procedural justice and democratic decision-making over distributive patterns.
} 
problem is that this seems to be a convincing claim only for those who share the intuition-it is going to be difficult to convince those who do not share it that this form of equality is indeed inherently wrong. ${ }^{19}$ One could also argue that social equality has constitutive value by claiming that it is part of a wider ideal, which is in of itself valuable. Social equality can be seen to be a necessary dimension of what it means to treat people as if they have equal moral worth. Consider Scheffler, for example, describing equality as an ideal which has social, political and moral dimensions, where the moral dimension 'asserts that all people are of equal worth and that there are some claims that people are entitled to make on one another simply by virtue of their status as persons' (Scheffler 2003, p. 22). Notions of equal moral worth (or what are commonly considered to be expressions of that worth, equal respect and concern) are often accepted as foundational assumptions underlying most contemporary theories of justice (Dworkin 1973, 2000; Kymlicka 2002; Christiano 2007. For a critique of the notion see Pojman 1997). As a basic moral assumption, equal moral worth is seldom argued for, and indeed, it is notoriously difficult to defend. ${ }^{20}$ These challenges have prompted Thomas Christiano, despite being an adherent of the notion of equal worth, to refer to it as 'one of the most profound problems of moral philosophy' (Christiano 2007, p. 54).

With reference to social equality then, as long as one accepts the assumption of equal moral worth, it seems fairly uncontroversial to claim that social equality is indeed valuable. A rather straightforward interpretation of equal moral worth would be likely to consider it incompatible with treating people as inferior or superior. However, for those who do not share this assumption, the value of social equality may remain obscure. As equal moral worth is such a challenging and entrenched problem, I cannot hope to present a suitable defence here-this would be a topic of its own. What we can emphasise, however, is that for some, treating individuals as inferior is clearly wrong or clearly a violation of equal moral worth, and if this is indeed so, then social equality is evidently valuable, however, these claims require an extended justification.

\section{The Harmful Effects of Social Inequality}

It is easier to point to the harmful consequences of status inequality to demonstrate that social equality is indeed valuable. The harmful effects that lead from inequality can be classified as (1) individual or (2) social. Individuals can be harmed by being treated as inferior, or as I will emphasise in some detail below, as superior. Someone who is treated as inferior could suffer damage to her self-respect, or her ability to

\footnotetext{
19 This is primarily a problem for the notion of intrinsic value, rather than for social equality specifically. However, there could be phenomena about which almost everyone shares the intuition that they are valuable in of themselves (pleasure is probably an example here), and these kind of phenomena may (1) indicate that the notion of intrinsic value is indeed meaningful and (2) call into question whether other notions, about which this intuition is not so widely shared, are then valuable in of themselves.

20 However, Williams (1972) provides an excellent analysis of how common humanity and equal respect as the foundations of a notion of equality, although admittedly 'vague and inconclusive' (p. 118), are not at all as trivial or lacking in substance as inegalitarians often claim.
} 
form her conception of the good could be compromised. ${ }^{21}$ Social inequality can also be said to cause harms to society-for example, more unequal societies seem to be unhealthier (Wilkinson 1996; Marmot and Wilkinson 2006). Wilkinson and Pickett (2009) have also claimed that a range of social harms, including obesity and crime, are associated with inequality, and particularly with relative inequalities, not merely absolute deprivation. Whether or not these individual or social harms do indeed result from social inequality is often, at least partially, an empirical question, and more empirical evidence may be needed to back-up some of the claims we could make about the harmful consequences of social equality. There is however already much empirical evidence to indicate that health is socially determined and that illhealth is likely to be associated with relative positions in a status hierarchy (Marmot 2005; Marmot and Wilkinson 2006). ${ }^{22}$ Stretching his discussion across both individual and social harms, Martin O'Neill emphasises that status inequalities can create the full range of harmful conditions that motivate us to condemn distributive inequalities, including objectionable inequalities in power and unhealthy fraternal social relations (O’Neill 2008, pp. 121-123, 126-130).

The harms of inequalities are usually discussed either in terms of the harms to the worst off or in terms of harms to society, or both. The potential harm associated with being on the other side of the unequal relationship-of being treated as superior-is neglected. ${ }^{23}$ This is regrettable-I think that hierarchies of status also have harmful implications for those who are treated as superior, beyond merely the effects they might feel in terms of harms to society. A morally distorted social system which falsely deems some to have lesser worth and others greater, is likely to harm not only those deemed inferior but also those considered superior.

As mentioned above in terms of the other harms associated with social inequality, the harms of being treated as superior should, at least partially, be identified and explicated by empirical research. However, drawing on interdisciplinary literature on oppression, the following list indicates what could be considered some of the primary ill effects of being treated as superior:

1. Impaired moral capacity: being treated as superior, particularly where this is associated with extreme social stratification and with oppression, could foster cruelty, a lack of empathy and inhumanity (see, for example, Freire 1996). ${ }^{24}$

\footnotetext{
21 See, for example, Rawls (1999: Sect. 67, pp. 386-391) and Honneth (1992) on the social basis of selfesteem and self-respect. See Kernohan (1998) on how inegalitarian attitudes and beliefs in an environment can distort conceptions of the good.

22 It is difficult to distinguish harms that could result from social inequality in isolation from overlapping or resulting inequalities or violations of justice. One could argue that the harms that ensue are due to the injustices rather than social inequalities per se, e.g. through overt discrimination or a lack of access to primary social goods. What is particularly interesting about the research on the social determinants of health, however, is that status in of itself seems to be linked to ill health, rather than (merely) material well-being and access to health care.

23 Contemporary notions of equality seem to neglect this aspect of inequality but earlier understandings at least tend to make reference to the harm of being treated as superior as well as that of being treated as inferior. Consider for example, Matthew Arnold, quoted by Tawney (1938, p. 1), 'On the one side... inequality harms by pampering'.

24 Perhaps one might be tempted to claim that this sees causation the wrong way around-it is cruel and inhumane people who develop these oppressive systems. Of course, it must be acknowledged that the
} 
Think of South Africa under apartheid. The harm that apartheid did to black and coloured people, as well as people of other non-Caucasian races, is evident. However, one could argue that whites were also harmed, albeit clearly not in the same way or to even nearly the same extent as other races. The constant tension or the threat of conflict between races, the demonization of blacks and the tenuousness of apartheid's purported justifications for a racial hierarchy, could be seen to have fostered fear, suspicion, and cruelty in many whites, which would influence not only their interactions with other races, but could permeate any of their relationships. Consider, for example, Desmond Tutu's claims about the harms of apartheid, based on his experiences as chair of the Truth and Reconciliation Commission:

This vicious system has had far more victims than anyone had ever thought possible, because it is no exaggeration to say that we have all in different ways been wounded by apartheid... In one way or another, as a supporter, a perpetrator, a victim, or one who opposed the ghastly system, something happened to our humanity... Those who were privileged lost as they became more uncaring, less compassionate, less humane and therefore less human.... Those who opposed apartheid could also end up... becoming like what they most abhorred (Tutu 1999, pp. 154-155).

2. Cognitive distortion: Being treated as superior could lead to self-deception as it may be necessary to develop a false notion of reality and a distorted conception of self and others in order to maintain belief in the 'justice' of the social system and to help to maintain a good conscience in the face of the humiliation and degradation of others (see, for example, Sue 2010, p. 128).

3. Emotional costs: whether as a result of the harms discussed above or for additional reasons, it seems feasible that being treated as superior could have severe emotional costs including heightened stress, anxiety and aggression. One of the sources of these emotional costs could be the pressure to meet unrealistic or elevated expectations and responsibilities - the pressure or the failure to meet these expectations is likely to be harmful. Think of traditional norms of masculinity which could demand of men that they remain strong and in control, and provide for their families. The pressure men may feel to meet these expectations or the failure they experience if they do not meet them could be linked to emotional breakdowns, stress-related illnesses and even aggression and violence (see, for example, Miles 1991).

Those treated as superior will also tend to be those who are better off in society (measured both in terms of overall resources and welfare), while those who are

Footnote 24 continued

main architects of morally reprehensible social systems along with many of their supporters are indeed cruel and inhumane, but it would be ridiculous to suggest that the social system itself did not have a profound influence on the people who lived within it. 
treated as inferior are likely to be worse off. However, the harms associated with higher status indicate that the 'better off' are not in an ideal position nor are they necessarily even in a particularly positive position. Furthermore, one could say that along certain dimensions of well-being they may be, at least, as badly off as those who are worst off overall. Consider, for example, what Martha Nussbaum refers to as 'affiliation':

'[b]eing able to live with and towards others, to recognize and show concern for other human beings, to engage in various forms of social interaction; to be able to imagine the situation of another and to have compassion for that situation; to have the capability for both justice and friendship (Nussbaum 2000, p. 79).

If we indeed recognise affiliation as an important dimension of well-being, it seems likely that the harms associated with having higher status - a distorted moral capacity, cognitive distortion and emotional costs-could severely diminish the capability for affiliation. Although, practically, identifying the harms of superior treatment may make no difference-after all this should not shift our concern from the worst off to the better off-it does imply that a society of equals could hold benefits for both the worst off and the better off, even if it demanded a decrease in overall or material well-being for the better off (a possibility, at least in principle, as I will explain in the next section).

In this section, I have focused a great deal on the implications of being treated as superior. However, the proportion of the discussion devoted to superior treatment is not intended as a reflection of the proportionality of harm and suffering associated with hierarchies of status. In other words, I am not saying that the harm suffered by those at the top is substantively or proportionally similar to those at the bottom, nor that we should be as concerned about the implications of treating people as superior as we should be with treating people as inferior. However, highlighting that being treated as superior can also be harmful has important implications for discussions about inequalities. Besides the fact that simply identifying and analysing these harms is significant precisely because they have been neglected, a particularly important implication is that the harms caused by superior treatment help to indicate that we should not be concerned merely with the position of the worst off. Although it is perfectly compatible to believe that both social equality and the level of welfare of the worst off are morally significant, if we focused primarily or exclusively on the welfare of the worst off we would not be able to recognise (and hence also, if necessary, address) the harms associated with superior treatment. However, this description is only a partial explanation for why a concern with social equality should not be reduced to a concern with the worst off-in the next section I consider how social equality avoids criticisms which claim that what seems to be a commitment to equality is often actually only a concern for overall welfare or the welfare of the worst off.

\section{Social Equality Versus Overall Welfare Or the Welfare of the Worst Off}

Highlighting the value of social equality by referring to its harmful effects may raise questions about whether social equality is indeed valuable. If we can only refer to 
the effects of a phenomenon to show its moral significance, then perhaps its effects are actually morally significant rather than the phenomenon itself. This is often considered to be the case with equality, with the implication that genuine egalitarianism stresses the intrinsic value of equality and not its effects, as inegalitarians such as utilitarians (who believe that we should maximise total welfare) or prioritarians (who believe that benefiting people matters more the worse off those people are) could also value equality instrumentally.

This particular concern, however, seems to be primarily relevant to equality of resources or welfare, and thus to distributive equality, rather than being applicable to social equality. Those who claim to be egalitarians have been accused of not actually valuing equality in of itself but rather valuing what an equal distribution (of money, for example) is able to achieve such as a maximisation of welfare or the best level of welfare for the worst off (Kagan 1998, pp. 48-54). Equality, here, is only instrumentally valuable. Advocating this kind of equality (and none other) is associated with what can be called 'Weak egalitarianism' (O'Neill 2008, p. 125).

Social equality, however, as I indicated in section "Intimations of Social Equality" is strongly egalitarian as it is both comparative and unspecific (Scanlon, n.d.). It appears to avoid the potential challenges associated with distributive equality because its concern is with hierarchical relationships which are necessarily comparative and which are foremost not related to specific levels of welfare. A hierarchy is necessarily comparative as it requires at least two interdependent ranks. Following on from Scanlon's discussion of the reasons why we object to inequality, Rawls puts it this way: 'High status assumes other positions beneath it; so if we seek a higher status for ourselves, we in effect support a scheme that entails others' having lower status' (Rawls 2001, p. 131). Rawls's description emphasises that a society of equals cannot mean that everyone has high status - this idea is incoherent as by its very nature, high status must assume the existence of low status. If we aim to remove the bottom layer of the hierarchy - those treated as inferior-we need to break the hierarchical relationship itself. Taking away the bottom layer means a qualitative change in the top layer, rather than moving those with low status to the rank of high status, or simply improving their level of welfare in ways which leave the hierarchy intact.

Highlighting the harms of superior treatment, as discussed in the previous section also helps us to keep in mind that it is the hierarchy itself that is the problem as it traps both those of higher and lower status in a dependent relationship. This implies that we cannot view those at the top of a hierarchy simplistically, merely as orchestrators of the inequalities who somehow benefit from the hierarchy without also being under its influence. Hierarchies of social value, besides the harms discussed, also restrict those of higher status. Indeed, those at the top of the hierarchy, who enjoy its privileges, could even be very much against it. I am not saying that those at the top bear no responsibility or have no power-they do-but I think it is important not to view them as somehow apart from the hierarchy that privileges them. They are themselves constrained by its rules and norms-usually constraints that help to keep the hierarchy intact. For example, contrary to the notion that the power of slave-owners was limitless, John Arthur points to restrictions placed on slave-owners, such as that they were forbidden to teach their slaves to 
read or write (Arthur 2007, pp. 93-94). A hierarchy does not imply that those at the top can do whatever they like, and where their privileges are likely to be constrained is particularly in their ability to subvert the hierarchy.

Furthermore, although social equality could have implications for resources or welfare, it is not primarily concerned with the actual levels of goods or well-being that those at the top or bottom of the hierarchy have, but rather with the relationship they have with each other. Ultimately, social equality is likely to lead to higher levels of overall welfare or improved welfare for the worst off (this is indicated by the extent of the harmful effects that result from social equality). However, these improvements in welfare would be viewed as a welcome consequence of equal social relations-we cannot simply say that social equality can be reduced to improving welfare. Considering the harmful effects of status hierarchies, it is likely that destroying a social hierarchy will always lead to improvements in the welfare of the worst off. If, however, social equality can be shown to be intrinsically valuable then there could, at least hypothetically, be cases where eliminating a status hierarchy would be valuable even if no-one's welfare was improved or even if the welfare of the worst off was decreased. This would then seem to evoke the Levelling Down Objection (LDO) against social equality. The LDO states that egalitarianism is problematic as it would value bringing about an overall decrease in welfare to the better off without increasing the overall welfare of anyone who is among the worst off (Parfit 1997).

There are two possible responses in terms of the LDO's applicability to social equality:

1. In the form presented by Parfit, the LDO would not apply to social equality as it is only intended to apply to telic forms of egalitarianism which value equality of welfare per se (Parfit 1997, pp. 204, 210-212). Social equality thus avoids the LDO as it indicates that levelling down is indeed valuable but not because equality of welfare is valuable per se, but in order to reduce or eliminate hierarchical relationships.

2. Martin O'Neill has argued, however, that the LDO can indeed be applied to other forms of egalitarianism (O'Neill 2008, pp. 140-152). However, he claims that pluralism provides a 'knockdown response' (O'Neill 2008, p. 143) to the LDO as 'unless we hold an implausible one-eyed egalitarianism that claims that egalitarian reasons should always trump all other reasons, and hence that we should always level down, the Levelling Down Objection is unproblematic' (O'Neill 2008, p. 144). Thus we can say that social equality would only be problematic if it had absolute priority over all other values, and thus, if this were the case, it would consistently advocate social equality over improving welfare. However, as long as we view social equality as one of a number of values, such as welfare, we will not necessarily advocate social equality when this does not improve welfare.

O'Neill goes on to explain that the pluralist response is definitive against the LDO in all but the starkest of cases, where levelling down would not lead to improvements in welfare for anyone and it would also not lead to a 'better state of affairs' for egalitarian reasons, such as an improvement in status equality (O'Neill 
2008, p. 150). A theory of social equality, however, would not advocate levelling down except in cases where status equality would be improved, and thus the starkest of cases should not follow from a commitment to social equality.

\section{Conclusion}

To summarise: Social equality is an opposition to hierarchies of social status which treat individuals as inferior or superior. Social inequalities are harmful, potentially intrinsically so, however they are more clearly harmful because they lead to a range of ill effects including to those of higher status.

My description of social equality is preliminary-necessarily so as it has been neglected as a topic and requires in-depth analysis from the ground up. We can use this preliminary, clarifying description to initiate a debate that could help in the development of a robust, comprehensive theory of social equality.

Acknowledgments This paper is based on a chapter of my $\mathrm{PhD}$ thesis although it has undergone substantial changes since my PhD was completed at University College London in 2007. I am very grateful to Jonathan Wolff, my $\mathrm{PhD}$ supervisor, for many helpful comments on my thesis and early versions of this paper. I am also grateful to Faith Armitage, Andrew Mason and Anne Phillips for providing useful feedback. More recent revisions have been undertaken with numerous helpful comments and suggestions from anonymous reviewers. As a part of my thesis, this paper was started with the financial support of a Commonwealth Scholarship, and revisions were undertaken with support from the Swiss National Science Foundation.

\section{References}

Anderson, Elizabeth S. 1999. What is the point of equality? Ethics 109: 287-337.

Anderson, Elizabeth S. 2010. Justifying the capabilities approach to justice. In Measuring justice: Primary goods and capabilities, ed. Harry Brighouse, and Ingrid Robeyns, 81-100. Cambridge: Cambridge University Press.

Arneson, Richard J. 1989. Equality and equal opportunity for welfare. Philosophical Studies 56: 77-93.

Arneson, Richard J. 2006. Distributive justice and basic capability equality: 'Good enough' is not good enough. In Capabilities equality: Basic issues and problems, ed. Alexander Kaufman, 17-44. New York, London: Routledge.

Arthur, John. 2007. Race, equality, and the burdens of history. Cambridge: Cambridge University Press. Bayly, Susan. 1999. Caste, society and politics in India from the eighteenth century to the modern age. Cambridge: Cambridge University Press.

Brown, Jennie. 1994. Medgar Evers. Los Angeles: Melrose Square Publishing.

Casal, Paula. 2007. Why sufficiency is not enough. Ethics 117: 296-326.

Christiano, Thomas. 2007. A foundation for egalitarianism. In Egalitarianism, ed. Nils Holtug, and Kasper Lippert-Rasmussen, 41-82. Oxford: Clarendon Press.

Crisp, Roger. 2003. Equality, priority and compassion. Ethics 113: 745-763.

Dahrendorf, Ralf. 1972. On the origin of social inequality. In Philosophy, politics and society: 2nd series, ed. Peter Laslett, and W.G. Runciman, 88-109. Oxford: Basil Blackwell.

Dworkin, Ronald. 1973. The original position. The University of Chicago Law Review 40: 500-533.

Dworkin, Ronald. 1981a. Equality of what? Part 1: Equality of welfare. Philosophy \& Public Affairs 10: 185-246.

Dworkin, Ronald. 1981b. Equality of what? Part 2: Equality of resources. Philosophy \& Public Affairs 10: 283-345.

Dworkin, Ronald. 2000. Sovereign virtue: The theory and practice of equality. Cambridge, MA: Harvard University Press. 
Frankfurt, Harry. 1987. Equality as a moral ideal. Ethics 98: 21-43.

Fraser, Nancy. 1997. Justice interruptus: Critical reflections on the postsocialist condition. New York, London: Routledge.

Freire, Paulo. 1996. Pedagogy of the oppressed (trans: Myra Bergman Ramos). Penguin: London.

Honneth, Axel. 1992. Integrity and disrespect: Principles of a conception of morality based on the theory of recognition. Political Theory 20: 187-201.

Kagan, Shelly. 1998. Normative ethics. Boulder, Colorado: Westview.

Kernohan, Andrew. 1998. Liberalism, equality and cultural oppression. Cambridge: Cambridge University Press.

Kymlicka, Will. 2002. Contemporary political philosophy: An introduction, 2nd ed. Oxford: Oxford University Press.

Louw, P.Eric. 2004. The rise, fall, and legacy of apartheid. London and Westport, Conn: Praeger.

Lucas, J.R. 1965. Against equality. Philosophy 40: 296-307.

Mandela, Nelson. 1995. A long walk to freedom: The autobiography of Nelson Mandela. London: Abacus.

Mason, Andrew. 2000. Equality, personal responsibility, and gender socialisation. Proceedings of the Aristotelian Society 100: 227-246.

Marmot, Michael. 2005. Status syndrome: How your social standing directly affects your health. London: Bloomsbury.

Marmot, Michael, and Richard Wilkinson (eds.). 2006. Social determinants of health, 2nd ed. Oxford: Oxford University Press.

Miles, Rosalind. 1991. The rites of man: Love, sex and death in the making of the male. London: Grafton Books.

Miller, David. 1995. Complex equality. In Pluralism, justice and equality, ed. David Miller, and Michael Walzer, 197-225. Oxford: Clarendon Press.

Miller, David. 1998. Equality and justice. In Ideals of equality, ed. Andrew Mason, 21-36. Oxford: Blackwell.

Nussbaum, Martha. 2000. Women and human development: The capabilities approach. Cambridge: Cambridge University Press.

O'Neill, Martin. 2008. What should egalitarians believe? Philosophy \& Public Affairs 36: 119-156.

Parfit, Derek. 1997. Equality and priority. Ratio 10: 202-221.

Pojman, Louis P. 1997. On equal human worth: A critique of contemporary egalitarianism. In Equality: Selected readings, ed. Louis P. Pojman, and Robert Westmoreland, 282-298. Oxford and New York: Oxford University Press.

Rawls, John. 1999. A theory of justice, revised ed. Oxford: Oxford University Press.

Rawls, John. 2001. Section 31: Comments on equality. In Justice as fairness: A restatement, ed. Erin Kelly. Cambridge, MA: Belknap.

Rousseau, Jean-Jacques. 1984 [1755] A discourse on inequality (trans: Cranston, M.). London: Penguin.

Runciman, W.G. 1967. 'Social' equality. The Philosophical Quarterly 17: 221-230.

Scanlon, Thomas M. 2000. The diversity of objections to inequality. In The ideal of equality, ed. Matthew Clayton, and Andrew Williams, 41-59. London: Macmillan.

Scanlon, T. M. n.d. When does equality matter? Unpublished paper. Available at http://www.political science.stanford.edu/politicaltheoryworkshop/0607papers/scanlonpaper.pdf. Accessed 8 July 2011.

Scheffler, Samuel. 2003. What is egalitarianism? Philosophy \& Public Affairs 31: 5-39.

Sen, Amartya. 1982. Choice, welfare and measurement. Oxford: Blackwell.

Sue, Derald Wing. 2010. Microaggressions in everyday life: Race, gender and sexual orientation. Hoboken, NJ: Wiley.

Tawney, R.H. 1938. Equality, 3rd ed. London: George Allen \& Unwin.

Temkin, Larry S. 1993. Inequality. New York, Oxford: Oxford University Press.

Temkin, Larry S. 2003. Egalitarianism defended. Ethics 113: 764-782.

Terreblanche, Sampie. 2003. A history of inequality in South Africa: 1652-2002. Pietermaritzburg: University of Kwazulu-Natal Press.

Tutu, Desmond. 1999. No future without forgiveness. London: Rider.

Walzer, Michael. 1983. Spheres of justice: A defense of pluralism and equality. Oxford: Martin Robertson.

Wilkinson, Richard G. 1996. Unhealthy societies: The afflictions of inequality. New York: Routledge.

Wilkinson, Richard, and Kate Pickett. 2009. The spirit level: Why more equal societies almost always do better. London: Allen Lane. 
Williams, Bernard. 1972. The idea of equality. In Philosophy, politics and society: 2nd series, ed. Peter Laslett, and W.G. Runciman, 110-131. Oxford: Blackwell.

Wolff, Jonathan. 1998. Fairness, respect and the egalitarian ethos. Philosophy \& Public Affairs 27: 97-122.

Young, Iris Marion. 1990. Justice and the politics of difference. Princeton, NJ: Princeton University Press. 